\title{
Estilos de liderança de professores: aplicando o modelo de estilos parentais
}

\author{
Ana Priscila Batista \\ Lidia Natalia Dobrianskyj Weber
}

\section{Resumo}

Professores orientam os comportamentos das crianças estabelecendo diferentes climas emocionais no uso das estratégias educativas em sala de aula. Esse trabalho busca delinear uma análise dos estilos de liderança de professores aplicando o modelo de estilos parentais. Inicialmente, foi feita uma análise de literatura realizando uma busca nas bases de dados: Scielo, Science Direct e Scopus, utilizando os descritores: teachers' leadership styles, teachers' teaching styles e school leadership. Com essa busca constatou-se que existem diversas definições, formas de análise e variáveis estudadas, conforme a teoria adotada. Posteriormente, foi realizada a análise da relação professor-aluno aplicando o modelo de estilos parentais, que apresenta uma análise do sistema das relações a partir de duas dimensões: responsividade e exigência. Assim, foram categorizados quatro estilos de liderança: autoritário, permissivo, negligente e participativo. Conclui-se que o modelo de estilo parental fornece uma boa base teórica para pautar a análise dos estilos de liderança de professores.

Palavras-chave: Interação professor-aluno, estilo parental, atitudes do professor.

\section{Teachers' leadership styles: applying the parental styles' model.}

\begin{abstract}
Teachers guide children's behavior by establishing different emotional climates in the use of educational strategies in the classroom. This paper seeks to outline an analysis of leadership styles of teachers applying the model of parenting styles. Initially, an analysis of literature by performing a search in the databases: Scielo, Science Direct and Scopus using the key words: teachers' leadership styles, teachers' teaching styles and school leadership. With this search we found that there are several definitions, methods of analysis and variables, as the espoused theory. Subsequently, we performed the analysis of teacher-student relationship by applying the model of parenting styles, which presents an analysis of the system of relationships from two dimensions: responsiveness and demandingness. So were categorized four leadership styles: authoritarian, permissive, neglectful, and authoritative. We conclude that the model of parenting style provides a good theoretical basis to guide the analysis of teachers' leadership styles.
\end{abstract}

Keywords: Teacher-student interaction, parenting style, teacher attitudes.

\section{Estilos de liderazgo de maestros: aplicando el modelo de estilos parentales}

\section{Resumen}

En lo que a comportamiento se refiere los maestros orientan a los niños estableciendo diferentes climas emocionales según el uso de estrategias educativas en aula. Este trabajo busca perfilar un análisis de los estilos de liderazgo de maestros por medio de la aplicación del modelo de estilos parentales. Inicialmente se hizo un análisis de literatura a partir de una búsqueda en las bases de datos Scielo, Science Direct e Scopus, utilizando las palabras clave teacher's leadership styles, teacher's teaching styles e school leadership. Los resultados permitieron constatar que existen diversas definiciones, métodos de análisis y variables estudiadas, de acuerdo con la teoría adoptada. Posteriormente se realizó el análisis de la relación profesor-alumno aplicando el modelo de estilos parentales que presenta un análisis de sistema de relaciones a partir de dos dimensiones: capacidad de respuesta y exigencia. Se categorizaron cuatro estilos de liderazgo: autoritario, permisivo, negligente y participativo. Se concluye que el modelo de estilo parental constituye buena base teórica para orientar el análisis de los estilos de liderazgo de maestros.

Palabras clave: Interacción profesor-estudiante, estilo parental, actitudes del profesor. 


\section{Introdução}

Sabe-se que a relação que a criança estabelece com o seu ambiente social direto, como a família e a escola, são críticos para seu desenvolvimento. Segundo Del Prette e Del Prette (2001), no contexto familiar e escolar, as crianças começam a aprender determinados padrões de comportamentos, além de ampliarem o conhecimento que possuem sobre os diferentes papéis que fazem parte da vida social. Assim, pode-se considerá-los contextos onde se desdobra muito do que acontece na sociedade, sendo que as primeiras aprendizagens são fundamentais para todo o desenvolvimento posterior da criança.

Segue daí a importância do estudo das interações que a criança estabelece em tais contextos, mais especificamente, daquelas estabelecidas com seus principais agentes socializadores, pais e professores. Weber (2008) afirma que uma das funções familiares mais pesquisadas na atualidade se refere à função parental, pois está intimamente relacionada ao desenvolvimento de crianças e adolescentes. Entretanto, assim como pais, os professores também são importantes agentes de socialização. De acordo com Ribeiro (2010), o papel do professor vem tornando-se mais amplo e complexo, deixando de ser apenas o transmissor de informações e passando a ser considerado parceiro na construção dos conhecimentos, o que implica novos saberes e atitudes que possibilitam aos estudantes integrar, no processo de aprendizagem das disciplinas, os aspectos cognitivo, afetivo e a formação de atitudes.

Os professores dos anos iniciais do Ensino Fundamental são os profissionais da escola que interagem mais diretamente com a criança nessa etapa da escolarização. Os professores utilizam várias técnicas para orientar os comportamentos das crianças, estabelecendo diferentes climas emocionais no uso das estratégias educativas em sala de aula, o que, baseado na literatura acerca de estilos parentais (Baumrind, 1966; Maccoby \& Martin, 1983), denominou-se no presente trabalho de estilos de liderança de professores. A análise de tais estilos a partir de como tal temática é tratada na literatura, bem como a partir de um modelo consolidado, como o é o de estilos parentais, é importante como forma de compreender tais interações e climas presentes na sala de aula, o que, por sua vez, pode repercutir sobre o comportamento da criança.

Dessa forma, nesse trabalho será apresentada uma breve explanação da literatura referente ao modelo de estilos parentais, uma análise de literatura acerca de como os estilos de liderança de professores vêm sendo estudados e uma análise das interações entre professores e alunos a partir do conceito de 'estilos de liderança de professores', aplicando o modelo de estilos parentais e considerando os anos iniciais do Ensino Fundamental. A escolha por esse período deveu-se ao fato de considerar que, em cada etapa de escolarização, a relação estabelecida entre professor e aluno apresenta características peculiares, que devem ser levadas em consideração ao realizar tal análise.

\section{Modelo de estilos parentais}

Baumrind (1966) foi a primeira a desenvolver uma análise acerca da interação pais-filhos. Ela especificou uma ampla função dos pais: o controle parental. Assim, os padrões de controle que ela descreveu, posteriormente chamados de estilos parentais, foram denominados: autoritário, autoritativo e permissivo. Em estudo posterior, Maccoby e Martin (1983) avançaram na tipologia por capturar os estilos parentais como uma função de duas dimensões: a responsividade e a exigência. A escala exigência refere-se às atitudes dos pais que buscam controlar o comportamento dos filhos de forma a impor limites e regras, ou seja, refere-se à monitoria e disciplina do filho. A escala responsividade refere-se à comunicação, envolvimento, reciprocidade e afetividade parental. De acordo com Darling e Steinberg (1993), a exigência refere-se à disposição dos pais para agirem como agentes socializadores, enquanto a responsividade refere-se ao reconhecimento dos pais da individualidade da criança. Assim, as duas dimensões refletem dois tipos de demandas: aquelas feitas pela sociedade sobre a criança (como a transmitida pelos pais) e aquelas feitas pela criança à sociedade.

As duas dimensões propostas por Maccoby e Martin (1983), quando cruzadas, geraram quatro estilos parentais: autoritário, autoritativo, indulgente e negligente, sendo esses dois últimos resultantes do desmembramento do estilo permissivo devido à diferenciação de graus distintos de responsividade. Assim, com base nessas duas dimensões, os autores definiram quatro estilos parentais: 1) Autoritativo: alta responsividade e exigência; 2) Autoritário: baixa responsividade e elevada exigência; 3) Indulgente: elevada responsividade e baixa exigência e 4) Negligente: baixa responsividade e exigência.

Darling e Steinberg (1993) revisaram a história do constructo de estilo parental e, a partir disso, propuseram um modelo a partir de três características dos pais que influenciam o desenvolvimento infantil: os valores e os objetivos que os pais têm ao socializar seus filhos, as práticas parentais usadas pelos pais para ajudar as crianças a atingir esses objetivos e o estilo parental, ou clima emocional, dentro do qual a socialização ocorre. Os autores reconhecem que tais processos podem variar em função de influências além do contexto imediato, tais como a cultura, classe ou composição familiar. Assim, estilo parental é definido como um conjunto de atitudes direcionadas à criança e que, tomadas em conjunto, criam um clima emocional no qual os comportamentos dos pais são expressos, enquanto que práticas parentais são definidas por conteúdo específico e operam em domínio circunscrito, tendo um efeito direto sobre o desenvolvimento de comportamentos específicos e características da criança. A partir dessa perspectiva, estilos parentais podem ser mais bem pensados como uma variável contextual que modera a relação entre práticas parentais específicas e resultados desenvolvimentais específicos. Ambos, estilo parental e práticas parentais, resultam em parte dos objetivos e valores que os pais apresentam. 


\section{Análise de literatura dos estilos de liderança de professores}

Ao se falar em estilos de liderança, é importante mencionar que o modelo de estilos parentais proposto por Baumrind (1966) é semelhante à tipologia sociológica das lideranças de grupo. Estudos iniciais em termos de climas de liderança foram realizados estabelecendo três tipos principais de liderança: democrática, autoritária e laissez-faire, bem como suas consequências sobre o desenvolvimento dos grupos. No estudo de Lewin, Lippitt e White (1939, citado por Chemers, 1997), profissionais foram treinados a liderar pequenos grupos de meninos a partir desses estilos de liderança. Líderes democráticos envolveram os meninos em decisões participativas acerca de atividades do grupo, enquanto nos grupos liderados de forma autoritária, todas as decisões foram tomadas pelo líder. Na condição laissezfaire, a atividade de liderar foi mantida em um mínimo, sendo que o líder permitia aos meninos trabalhar e brincar sem nenhuma supervisão.

No trabalho de White e Lippitt (1969), as características em cada estilo de liderança e alguns resultados dos comportamentos dos meninos submetidos a cada um deles são descritos a partir dos estudos de Lippitt (1940) e Lippitt e White (1943). No estilo autoritário, o líder era quem determinava as atividades e regras, determinava o passo específico de trabalho e o companheiro de cada um. Esse líder tendia a ser pessoal no elogio e na crítica do trabalho de cada um. Os meninos submetidos a esse estilo apresentaram mais comportamento submisso ou dependente do líder, comportamento agressivo, a conversa era menos variada e houve bastante descontentamento. No estilo democrático, todas as situações eram uma questão de discussão e decisão do grupo, estimuladas e assistidas pelo líder, que era objetivo ou dirigido pelos fatos, em seus elogios ou críticas. Os membros tinham liberdade para trabalhar com quem escolhessem e a divisão de trabalho era deixada para o grupo. Entre os meninos submetidos a esse estilo, a motivação para o trabalho era mais intensa, havia mais espírito de grupo e amizade, era maior a frequência de conversa amistosa, confiante, de sugestões voltadas para o grupo, além de haver maior originalidade. No estilo laissez-faire acontecia uma completa liberdade para a decisão do grupo, com um mínimo de participação do líder. Vários materiais eram apresentados pelo líder, que deixava claro que daria informações quando solicitado, não tendo outra participação na discussão do trabalho. No grupo de meninos, havia menos trabalho e esse era de pior qualidade, sendo que as atividades eram caracterizadas pela brincadeira.

Em relação à liderança no contexto escolar, sabe-se que há uma diversidade de definições, a partir de diferentes teorias. Para exemplificar, Smith e Piele (2006) propõem que a definição de liderança em escolas deve incluir as dimensões influência, competência, moral, transformação e finalidade desejada. Os autores mencionados acima, bem como Rodríguez e Hovde (2002), citam o estudo de Leithwood e Duke (1998), que examinaram artigos sobre liderança educacional publicados entre 1985 a 1995 e, a partir disso, identificaram conceitos distintos de liderança: 1. Instrucional; 2. Transformacional; 3. Moral; 4. Participativa; 5. Diretiva/administrativa. Rodríguez e Hovde (2002) afirmam que, apesar dos debates entre os defensores desses modelos de liderança, eles não são necessariamente mutuamente excludentes e, para resolver alguns problemas ou situações específicas, muitas vezes há a necessidade de uma variedade de estilos. Analisando esses estilos de liderança escolar, percebe-se que os mesmos estão mais voltados para a direção e administração escolar, não especificamente para a relação estabelecida entre professor e aluno em sala de aula.

Dessa forma, buscou-se realizar uma análise da literatura acerca de como os estilos de liderança vêm sendo estudados no contexto escolar. Para isso, foi realizada uma busca nas bases de dados: Scielo, Science Direct e Scopus, utilizando os descritores: estilo de liderança de professores (teachers' leadership styles), estilos de ensino de professores (teachers' teaching styles) e liderança escolar (school leadership). Foram excluídos textos referentes à validação de instrumentos e à formação docente, relacionados ao ensino superior e ao ensino de conteúdos específicos, bem como aqueles que não eram referentes ao contexto escolar.

Os artigos encontrados foram analisados quanto ao objetivo do estudo e inseridos nas seguintes categorias: 1 ) Artigos relacionados aos comportamentos do professor e/ou aos efeitos sobre os comportamentos dos alunos; 2) Artigos relacionados à interação entre escola e/ou alunos e/ou pais e/ou comunidade; 3) Artigos de pesquisa relacionados aos comportamentos e/ou à interação entre escola, direção escolar, equipe pedagógica e professores.

Observou-se, na Categoria 1, que práticas consideradas positivas estão relacionadas a resultados positivos em relação a melhor desempenho dos alunos nas mais diversas áreas (Abrantes, Seabra, \& Lages, 2007; Baker, 2006; Burchinal, Peisner-Feinberg, Pianta, \& Howes, 2002; Buyse, Verschueren, Doumen, Van Damme, \& Maes, 2008; Connor, Son, Hindman, \& Morrison, 2005; Guo, Piasta, Justice, \& Kaderavek, 2010; Hughes, Zhang, \& Hill, 2006). Também se observou que a maioria desses estudos mencionou a dimensão responsiva e afetiva dessas práticas, referindo-se: à responsividade do professor (Abrantes e cols., 2007), à relação mais estreita com o professor (Baker, 2006), ao apoio emocional dos professores (Buyse e cols., 2008), a professores mais calorosos e sensíveis (Connor e cols., 2005) e ao suporte professor-aluno em sala de aula (Hughes e cols., 2006). Alguns estudos também se referiram: à existência de congruência entre crenças e práticas reais em sala de aula (Eveyik-Aydın, Kurt, \& Mede, 2009); à relação entre práticas de ensino efetivas e nível de satisfação com o trabalho (Opdenakker \& Van Damme, 2006); à interação significativa entre a autoeficácia de professores, a qualidade em sala de aula e os ganhos de vocabulário (Guo e cols., 2010); às avaliações negativas das crianças pelos professores preditas por comportamentos negativos do professor e clima em sala de aula menos ideal (Brophy-Herb, Lee, Nievar, \& Stollak, 2007). 
Na categoria 2 (artigos relacionados à interação entre escola e/ou alunos e/ou pais e/ou comunidade), observou-se que as conclusões dos estudos foram relacionadas a vários aspectos. Foram abordados em alguns estudos: o efeito de algumas formas de liderança dos administradores da escola sobre o desempenho acadêmico dos alunos (Heck \& Hallinger, 2010; Kythreotis, Pashiardis, \& Kyriakides, 2010; Marks \& Printy, 2003); a importância de envolver os diretores escolares em esforços de parceria com pais, professores e membros da comunidade e continuamente expandir e avaliar o trabalho da equipe de parceria para promover o sucesso e desenvolvimento do aluno (Van Voorhis \& Sheldon, 2004); a criatividade do diretor da escola como um fator principal para estabelecer uma comunicação forte entre a escola e os pais (Athanasoula, Reppa, Botsari, \& Sarantos, 2010); as práticas específicas de liderança dos diretores que permitem servir eficazmente as escolas (Sanzo, Sherman, \& Clayton, 2011).

Na Categoria 3 (artigos de pesquisa relacionados aos comportamentos e/ou à interação entre escola, direção escolar, equipe pedagógica e professores), a maioria dos estudos abordou o efeito dos estilos de liderança e comportamentos de administradores da escola sobre a escola como um todo e sobre diversos comportamentos do professor. Algumas conclusões foram: existência de uma relação positiva entre os comportamentos de liderança instrucional dos diretores e atitudes dos professores para a mudança organizacional (Kursunoglu \& Tanrıogen, 2009); uma relação significativa e positiva entre os comportamentos organizacionais dos professores e os estilos de liderança transacional e transformacional dos administradores escolares (Oguz, 2010); o impacto da liderança diretiva sobre o desempenho dos professores foi contingente, sendo que o efeito positivo da liderança participativa sobre o desempenho dos professores foi acima e além das condições específicas estudadas (Somech \& Wenderow, 2006); uma relação significativa entre a criatividade organizacional e os comportamentos de liderança ética dos diretores, em relação às dimensões da ética ambiental, tomada de decisão ética e ética comportamental (Yilmaz, 2010); existência de uma relação paralela entre a eficácia das escolas e as altas habilidades de liderança possuídas pelos gestores (Zembat, Koçyigit, Tugluka, \& Dogan, 2010); relação positiva existente entre a liderança diretiva e comprometimento organizacional e desempenho dos funcionários da equipe escolar, bem como uma relação positiva entre a liderança participativa e empoderamento dos professores (Somech, 2005); a liderança transformacional foi positivamente associada com clima de inovação das escolas e quanto mais os diretores estavam intimamente ligados aos seus professores, mais dispostos os professores estavam a investir na mudança e na criação de novos conhecimentos e práticas (Moolenaar, Daly, \& Sleegers, 2010); o uso frequente de práticas de liderança efetivas foi positivamente associado com o progresso de melhoria escolar e clima de eficácia escolar (Orr \& Orphanos, 2011); a liderança do professor foi considerada para capacitação de professores e contribuiu para a melhoria da escola (Muijs \& Harris, 2006); a importância do reconhecimento das emoções dos líderes das escolas dentro de programas de preparação (Schmidt, 2010; Wallace, 2010).

De forma geral, foi possível constatar que a literatura sobre estilos de liderança no contexto escolar, seja do professor ou dos administradores, é bastante vasta. Com isso, fica clara a diversidade de definições do conceito de liderança de professores utilizadas nos estudos, bem como diversas formas de análise e variáveis estudadas, conforme a teoria adotada. Enquanto alguns estudos se voltam para a relação entre professor-aluno, outros se voltam para a liderança escolar e abordam aspectos mais amplos referentes à gestão escolar. Além disso, percebeu-se que as práticas dos professores podem ser analisadas a partir de diferentes perspectivas teóricas.

Além dessa busca realizada, foram encontrados dois artigos que fazem a análise dos estilos de liderança no contexto escolar a partir do modelo de estilos parentais (Gill, Ashton, \& Algina, 2004; Pellerin, 2005). Gill e cols. (2004) propõem que o constructo de escolas autoritativas pode capturar as dimensões exigência acadêmica e responsividade para demonstrar que ambas são necessárias para um melhor desenvolvimento dos estudantes. A partir disso, buscaram verificar se essas dimensões eram preditoras de sucesso matemático, envolvimento e lócus de controle. Dados de 19.435 alunos de 11 a 14 anos mostraram que as percepções dos estudantes acerca da responsividade da escola foram relacionadas ao envolvimento e percepção do controle interno, mas não foram relacionadas à realização acadêmica, o que indica relação entre responsividade da escola e resultados afetivos. As percepções da exigência da escola não foram relacionadas aos resultados dos estudantes e, em soma, não foi encontrada clara evidência suportando ambas as dimensões da escola autoritativa. Os autores sugerem medidas mais precisas e mais fundamentadas na teoria de exigência e responsividade. Além disso, ressaltam que esse estudo focou em escolas de ensino médio devido, dentre outros, à preocupação atual do declínio de motivação durante esses anos. No entanto, acreditam que a construção da escola autoritativa, medida pelas dimensões de responsividade e exigência, tem relevância do pré-escolar aos anos da faculdade, e encorajam uma investigação mais aprofundada em todos os níveis escolares.

Pellerin (2005) afirma que a literatura de clima escolar sugere que escolas que são ambas responsivas e exigentes alcançam os melhores resultados com estudantes. Seu estudo foi realizado com 4.743 alunos de 14 a 18 anos, buscando investigar o efeito do estilo da escola sobre o não envolvimento estudantil, especificamente no que se refere a faltas, evasão e abandono escolar. Os resultados indicaram que escolas participativas apresentam os melhores resultados e escolas indiferentes/negligentes os piores resultados para o não envolvimento, enquanto as escolas autoritárias têm os piores resultados para a evasão escolar. A autora conclui que esses resultados são consistentes com as descrições dos quatro estilos parentais e suportam a aplicação desses estilos para a escola. Como os pais participativos, 
escolas participativas mantêm alunos com altos padrões e relações responsivas.

Apesar dos resultados serem distintos, esses estudos mostraram que a exigência e a responsividade utilizadas pela escola e por professores, em certa medida, influenciam o comportamento dos alunos. Ambos os estudos foram realizados com adolescentes e deve-se considerar que, nesse período, essa população, além de apresentar padrões comportamentais já bem estabelecidos devido a uma história de interação com o contexto escolar, também influencia e é influenciada por diversos contextos em que se insere, tais como família, escola, amigos, comunidade. Gill e cols. (2004) ressaltam a importância de se investigar as dimensões de responsividade e exigência em todos os níveis escolares. Assim, considera-se que a influência de tais dimensões pode ser diferente conforme a etapa da escolarização. Nos anos iniciais do Ensino Fundamental, as crianças passam boa parte do dia na escola e ainda estão passando pelas primeiras aprendizagens em relação a diversos aspectos. Além disso, família e escola são contextos que exercem grande influência nessa etapa do desenvolvimento.

\section{Análise dos 'estilos de liderança de professores' dos anos iniciais do Ensino Fundamental, aplicando o modelo de estilos parentais}

Antes de se iniciar a análise, é importante considerar que diversos fatores estão presentes e influenciam o comportamento do professor em relação ao aluno, tais como: o comportamento dos alunos, de outros professores, de demais profissionais da escola, exigências da escola e instâncias superiores, planos de aula a cumprir, condições de trabalho, o comportamento dos pais, crenças sobre os alunos e suas famílias, situações presentes na vida pessoal, história passada vivida com seus professores, formação profissional, contextos social, político, econômico e cultural em que se inserem (Pereira, Marinotti, \& Luna, 2004; Batista \& Weber, 2011). Esses fatores devem ser considerados em uma análise mais ampla e completa de tal contexto, entretanto, o presente texto irá deter-se numa análise da interação professor-aluno a partir de variáveis presentes em sala de aula. A partir da literatura da área de estilos parentais, acredita-se que as dimensões relacionadas à exigência $e$ à responsividade podem ser utilizadas para compreender os estilos de liderança de professores das séries iniciais do Ensino Fundamental.

Antes de se demonstrar tal análise, destaca-se que, de acordo com a perspectiva da análise do comportamento, referencial adotado para a presente análise, o indivíduo modifica o meio na medida em que é modificado por ele, em uma relação de interdependência mútua (Skinner, 1998). Assim, pode-se dizer que, na interação entre professor e aluno, há uma relação de influência recíproca entre o comportamento dos envolvidos. Assim, pode-se considerar que a forma como os professores interagem com seus alunos e o clima emocional presente na sala de aula influenciam o comportamento da criança que, por sua vez, influencia as habilidades utilizadas pelos professores no dia a dia da sala de aula.

A partir do artigo de Darling e Steinberg (1993), também se pode pensar em três características dos professores, semelhante às dos pais, que influenciam o desenvolvimento infantil: 1) os valores e os objetivos que os professores têm quanto ao ensino de conteúdos e habilidades, 2) as práticas usadas para ajudar as crianças a atingir estes objetivos e 3) o estilo de liderança, ou clima emocional, dentro do qual essa relação de ensino-aprendizagem ocorre. Assim como os autores também o fizeram, é importante considerar aqui o fato de que tais processos podem variar como função de influências além do contexto imediato, tais como a cultura ou classe. Assim, o estilo de liderança dos professores pode ser definido como um conjunto de atitudes direcionadas aos alunos e que, tomadas em conjunto, criam um clima emocional no qual os comportamentos são expressos, moderando a efetividade de uma prática particular e alterando a receptividade da criança a essa relação de ensino-aprendizagem. Os comportamentos, que podem ser denominados de estratégias ou práticas educativas, são definidos por conteúdo específico, tendo um efeito direto sobre o desenvolvimento de comportamentos específicos da criança. Tanto os estilos de liderança quanto as práticas educativas específicas resultam em parte dos objetivos e valores que os professores apresentam a partir de sua história de vida e do contexto em que estão inseridos.

Assim, os quatro estilos de liderança serão analisados a seguir como sendo o clima emocional, com o predomínio de determinadas contingências em sala de aula, no qual tomam lugar as práticas educativas de conteúdos específicos, sejam do domínio acadêmico/cognitivo, social ou afetivo. Para tanto, inicialmente serão consideradas as dimensões exigência e responsividade do professor no contexto da sala de aula, pois tais dimensões cruzadas compõem os quatro estilos de liderança.

A exigência pode ser considerada em relação às atitudes dos professores de monitorar e controlar o comportamento dos alunos de forma a impor limites e regras na sala de aula e também no contexto escolar. A responsividade pode referir-se à comunicação, envolvimento, reciprocidade e afetividade do professor em relação aos alunos. Aqui também vale a afirmação de Darling e Steinberg (1993) de que as duas dimensões refletem dois tipos de demandas: aquelas feitas pela sociedade sobre a criança e aquelas feitas pela criança à sociedade. A primeira demanda pode ser compreendida como o fato de ser esperado que a criança apresente comportamentos, conhecimentos e habilidades importantes para o convívio em sociedade. Assim, espera-se que a escola cumpra com sua função socializadora, pois, conforme mencionado em documentos oficiais ${ }^{1}$, a educação é dever da família e do Estado, enfatizando a formação do cidadão que compreende seu ambiente social com atitudes e valores que fortalecem a vida em sociedade. A segunda

1 Lei de Diretrizes e Bases da Educação Nacional - LDB (BRASIL, 1996) e Plano Nacional de Educação - PNE (BRASIL, 2001). 
demanda reflete o fato de a criança ter suas necessidades e direitos acolhidos pela escola, no papel que compete a ela, pois, conforme o Estatuto da Criança e do Adolescente (Brasil, 1990, art. 53), "a criança e o adolescente têm direito à educação, visando ao pleno desenvolvimento de sua pessoa, preparo para o exercício da cidadania e qualificação para o trabalho, assegurando-lhes: I - igualdade de condições para o acesso e permanência na escola; II - direito de ser respeitado por seus educadores", dentre outros.

$\mathrm{Na}$ presença de responsividade, é esperado que as crianças sintam-se respeitadas, além de estarem em um ambiente acolhedor, alegre, no qual o aprender aconteça de forma prazerosa. Percebe-se que, para essa dimensão, as contingências positivamente reforçadoras estão presentes. $\mathrm{O}$ fato de a criança e de seus comportamentos adequados serem valorizados pode propiciar a autoestima e a autoconfiança, sentimentos importantes para o desenvolvimento das mesmas nas mais diversas áreas.

No contexto da sala de aula e da escola, a exigência pode ser caracterizada pelos seguintes comportamentos dos professores: estabelecimento de regras de acordo com as características das crianças; clareza nas instruções fornecidas; consequências para o não cumprimento das regras; não aceitação de comportamentos inadequados e consequenciação dos mesmos; estabelecimento de regras básicas de convivência, tais como a de esperar a sua vez e a dividir materiais tanto em trabalhos individuais como em grupo; cobrar e corrigir tarefas para casa conforme o desempenho; consistência do comportamento do professor, por exemplo, se, quando diz que vai fazer algo, faz de acordo com o combinado; coerência, por exemplo, quando o professor diz "não", ele se mantém firme mesmo diante de reclamações, entretanto há existência de flexibilidade conforme o contexto. Comportamentos inseridos na dimensão de exigência podem estar ocorrendo sob controle de contingências aversivas (reforçamento negativo e punição) ou positivas.

A partir da análise de tais dimensões, serão descritos os quatro estilos de liderança dos professores. O estilo autoritativo pode ser considerado aquele que combina as dimensões de responsividade e exigência de forma equilibrada. Esse estilo implica que, ao mesmo tempo em que o professor apresenta claramente o nível de exigência da escola e da sala de aula pelo estabelecimento de regras, limites e monitoria do comportamento, também há presença de afetividade nas relações. Predominantemente estão presentes contingências positivamente reforçadoras, mas podem aparecer contingências aversivas amenas, para a consequenciação de comportamentos inadequados. Propiciam atividades que estimulam o aspecto físico, cognitivo, afetivo e social da criança, de forma afetiva, em um ambiente agradável e acolhedor de aprendizagem nas mais diversas situações, mantendo-se claros e coerentes em relação aos limites e regras da escola e da sala. Esses professores propõem atividades, exigem obediência, mantêm a autoridade, fazem uso de explicações, entretanto são abertos para trocas com as crianças, elogiam e recompensam quando elas se comportam de forma adequada, consideram os sentimentos e as opiniões delas, fornecem alternativas e fazem-nas participar das decisões, permitindo o desenvolvimento da autonomia.

No estilo de liderança autoritário predomina a alta exigência e a baixa responsividade. São professores que valorizam a autoridade, a ordem e a estrutura tradicional sem atentar às demandas da criança. Buscam a obediência das crianças sem considerar que, nessa etapa da escolarização, eles precisam ensiná-las a seguir regras. Não permitem que elas participem de decisões, consideram pouco o que as crianças sentem ou falam e não demonstram interesse e afetividade por elas.

No estilo permissivo, os professores são muito responsivos e não exigentes. Não estabelecem regras e limites apropriados e não monitoram os comportamentos, realizando os desejos da criança. Nesse estilo, a maior parte das contingências são positivamente reforçadoras, tanto para comportamentos adequados quanto para inadequados. São aqueles professores que deixam as crianças fazerem o que querem. Muitas vezes valorizam a opinião das crianças e deixam a autoridade de lado.

No estilo negligente, os professores não são responsivos nem exigentes. Ao mesmo tempo em que não estabelecem regras e limites, não monitoram o comportamento dos alunos, também não se envolvem e não são afetivos com as crianças. Pode-se dizer que há poucos comportamentos dos professores que são contingentes aos comportamentos dos alunos, ou seja, os professores não consequenciam de forma a reforçar ou punir o comportamento das crianças. Podem ser considerados, de certa forma, negligentes aqueles professores que apenas ministram a aula expondo os conteúdos propostos, sem atentar às necessidades e dúvidas das crianças. Podem ser aqueles professores que estão sobrecarregados com várias atividades ou apresentam problemas pessoais ou não gostam da profissão, mas se veem obrigados a exercê-la por precisarem do dinheiro e não têm alternativa.

Além dos estilos de liderança propostos a partir das dimensões de responsividade e exigência, acredita-se que se deve levar em consideração a presença de contingências aversivas na interação professor-aluno. Segundo Sidman (1995), a coerção, uma forma comum utilizada para persuadir o comportamento dos outros, também está presente em sala de aula, e as crianças que aprendem sob essas contingências crescem menosprezando seus professores e odiando a escola. Independente do estilo de liderança adotado, em alguns momentos, o professor pode estabelecer contingências coercitivas de forma a punir inadequadamente 0 comportamento dos alunos, o que pode ser influenciado por diversos fatores. Assim, acredita-se que se deve considerar também a frequência de tais situações aliada ao estilo do professor para se determinar o efeito sobre o clima presente em sala de aula e sobre o comportamento dos alunos.

De forma geral, a partir dessa análise, pode-se dizer que a escola e o professor podem se apresentar como fatores de proteção ou até mesmo de risco para o desenvol- 
vimento da criança. O estilo autoritativo configura-se como sendo de proteção, pois os professores se comportam com exigência e responsividade de forma equilibrada e, muitas vezes, as crianças não encontram isso no ambiente familiar e em demais contextos em que estão inseridas. Não há dúvida de que tanto as crianças cujos pais utilizam estratégias disciplinares que equilibram regras e afeto, quanto aquelas cujos pais mostram estratégias inadequadas, tendem a se beneficiar quando os professores se comportam dessa forma, pois é com eles que a criança passa uma parte do dia e é nesse contexto que várias aprendizagens tomam lugar. Isso vem ao encontro do apresentado anteriormente na revisão de literatura, em que vários artigos mencionaram que práticas consideradas positivas estavam relacionadas a resultados positivos e melhor desempenho dos alunos nas mais diversas áreas.

É importante considerar que a criança já apresenta formas de se comportar que foram aprendidas no seu ambiente familiar, nas interações com professores anteriores, com pares e comunidade em que está inserida. Algumas já obedecem quando os professores dizem "não", enquanto outras insistem ou não atendem às ordens dadas. Podem existir aquelas que não sabem como responder à responsividade, pois suas relações anteriores não eram desse modo. Essa diversidade de comportamentos em um mesmo contexto, sala de aula, deve ser considerada, e o professor deve estar sensível à individualidade de cada um ao mesmo tempo em que mantém as mesmas regras para toda a turma, o que não é considerado uma tarefa fácil e exige habilidade e conhecimento.

Também é importante considerar que, além dos professores se preocuparem com a didática adequada para o ensino de conteúdos acadêmicos específicos, cada vez mais se enfatiza a necessidade da escola e do professor trabalhar aspectos referentes ao desenvolvimento como um todo, inserindo aí a formação de valores. Conforme Novak e Pelaez (2004), as escolas são uma importante fonte de transmissão social, pois a entrada no sistema educacional expõe a criança a valores extrafamiliares. Assim, as funções da educação se referem tanto ao aumento do desenvolvimento cognitivo da criança quanto à promoção do seu desenvolvimento social. Entretanto, os professores nem sempre estão preparados, o que pode se dar devido ao fato de não terem uma formação ou capacitação adequada.

\section{Considerações finais}

Com esse trabalho observou-se a importância de um olhar especial para os estilos de liderança de professores dos anos iniciais do Ensino Fundamental, pois se trata de um período em que a criança está passando pelas primeiras aprendizagens em relação a diversos aspectos, o que pode influenciar e repercutir sobre suas aprendizagens futuras. Considera-se primordial olhar como ocorre a interação estabelecida entre professor e aluno, pois o desenvolvimento de crianças também é uma responsabilidade do professor e da escola.

Conclui-se que o modelo de estilo parental, juntamente com a análise do controle coercitivo, fornece uma boa base teórica para pautar a análise dos estilos de liderança de professores, pois as dimensões analisadas também estão presentes na relação professor-aluno. Nesse sentido, percebe-se a importância de estudos que descrevam e discutam melhor essas dimensões; que verifiquem o efeito de tais estilos sobre o comportamento de crianças; que investiguem os objetivos e valores dos professores que influenciam seus estilos de liderança, dentre outros. Assim, percebe-se que ainda há muito a ser investigado acerca de tal temática, sendo que a exploração de tais aspectos poderá contribuir para propostas de planejamento eficazes para o contexto escolar.

\section{Referências}

Abrantes, J. L., Seabra, C., \& Lages, L. F. (2007). Pedagogical affect, student interest, and learning performance. Journal of Business Research, 60, 960-964.

Athanasoula, A., Reppa, E. M., Botsari, K. K., \& Sarantos P. (2010). School leadership innovations and creativity: The case of communication between school and parents. Procedia Social and Behavioral Sciences, 2, 2207-2211.

Baker, J. A. (2006). Contributions of teacher-child relationships to positive school adjustment during elementary school. Journal of School Psychology, 44, 211-229.

Batista, A. P., \& Weber, L. N. D. (2011). Estilos de liderança de professores da educação infantil: uma análise a partir do modelo de estilos parentais. Em S. R. G. Pietrobon \& N. T. Ujiie (Orgs.), Educação Infantil: Saberes e Fazeres. Curitiba: Ed. CRV.

Baurimd, D. (1966). Effects of Authoritative Parental Control on Child Behavior. Child Development, 37, 887-907.

Brophy-Herb, H. E., Lee, R. E., Nievar, M. A., \& Stollak, G. (2007). Preschoolers' social competence: Relations to family characteristics, teacher behaviors and classroom climate. Journal of Applied Developmental Psychology, 28, 134-148.

Burchinal, M. R., Peisner-Feinberg, E., Pianta, R., \& Howes, C. (2002). Development of Academic Skills from Preschool Through Second Grade: Family and Classroom Predictors of Developmental Trajectories. Journal of School Psychology, 40(5), 415-436.

Buyse, E., Verschueren, K., Doumen, S., Van Damme, J., \& Maes, F. (2008). Classroom problem behavior and teacher-child relationships in kindergarten: The moderating role of classroom climate. Journal of School Psychology, 46, 367-391

Chemers, M. M. (1997). An integrative model of leadership. London: Psychology Press. 
Connor, C. M., Son, C. H., Hindman, A. H., \& Morrison. F. J. (2005). Teacher qualifications, classroom practices, family characteristics, and preschool experience: Complex effects on first graders' vocabulary and early reading outcomes. Journal of School Psychology, 43, 343-375.

Darling, N., \& Steinberg, L. (1993). Parentng Style as context: an integrative model. Psychological Bulletin, 113(2), 487-496.

Del Prette, Z. A. P., \& Del Prette, A. (2001). Psicologia das relações interpessoais: vivências para o trabalho em grupo. Petrópolis, RJ: Vozes.

Eveyik-Aydın, E., Kurt, G., \& Mede, E. (2009). Exploring the relationship between teacher beliefs and styles on classroom management in relation to actual teaching practices: a case study. Procedia Social and Behavioral Sciences, 1, 612-617.

Gill, M. G., Ashton, P., \& Algina, J. (2004). Authoritative schools: a test of a model to resolve the school effectiveness debate. Contemporary Educational Psychology, 29, 389-409.

Guo, Y., Piasta, S. B., Justice, L. M., \& Kaderavek, J. N. (2010). Relations among preschool teachers' self-efficacy, classroom quality, and children's language and literacy gains. Teaching and Teacher Education, 26, 1094-1103.

Heck, R. H., \& Hallinger, P. (2010). Testing a longitudinal model of distributed leadership effects on school improvement. The Leadership Quarterly, 21, 867-885.

Hughes, J. N., Zhang, D., \& Hill, C. R. (2006). Peer assessments of normative and individual teacher-student support predict social acceptance and engagement among low-achieving children. Journal of School Psychology, 43, 447-463.

Kursunoglu, A., \& Tanrıgen, A. (2009). The relationship between teachers' perceptions towards instructional leadership behaviors of their principals and teachers' attitudes towards change. Procedia Social and Behavioral Sciences, 252-258.

Kythreotis, A., Pashiardis, P., \& Kyriakides, L. (2010). The influence of school leadership styles and culture on students' achievement in Cyprus primary schools. Journal of Educational Administration, 48(2), 218-240.

Lippit, R. (1940). An experimental study of the effect of democratic and authoritarian group atmospheres. University of lowa Studies in Child Welfare, 16, 43-95.

Lippit, R., \& White, R. K. (1943). The social climate of children'sgroups. Journal of Social Psychology, 10, 271-301

Macoby, E., \& Martín, J. (1983). Socialization in the context of the family: parent-child interaction. Em E. M. Htherington (Org.) \& P. H. Mussem (Org. Série), Handbook of child psychology: Socialization, Personality and Social Development (pp. 1-101). New York: Wiley.
Marks, H. M., \& Printy, S. M. (2003). Principal Leadership and School Performance: An Integration of Transformational and Instructional Leadership. Educational Administration Quarterly, 39(3), 370-397.

Moolenaar, N. M., Daly, A. J., \& Sleegers, P. J. C. (2010). Occupying the Principal Position: Examining Relationships Between Transformational Leadership, Social Network Position, and Schools' Innovative Climate. Educational Administration Quarterly, 46(5) 623-670.

Muijs, D., \& Harris, A. (2006). Teacher led school improvement: Teacher leadership in the UK. Teaching and Teacher Education, 22, 961-972.

Novak, G., \& Peláez, M. (2004). Child and adolescent development: a behavioral systems approach. Califórnia: Sage Publications.

Oguz, E. (2010). The relationship between the leadership styles of the school administrators and the organizational citizenship behaviours of teachers. Procedia Social and Behavioral Sciences, 9, 1188-1193.

Opdenakker, M. C., \& Van Damme. J. (2006). Teacher characteristics and teaching styles as effectiveness enhancing factors of classroom practice. Teaching and Teacher Education, 22, 1-21.

Orr, M. T., \& Orphanos, S. (2011). How Graduate-Level Preparation Influences the Effectiveness of School Leaders: A Comparison of the Outcomes of Exemplary and Conventional Leadership Preparation Programs for Principals. Educational Administration Quarterly, 47(1), 18 -70.

Pellerin, L. A. (2005). Applying Baumrinds parenting typology to high schools: toward a middle-range theory of authoritative socialization. Social Science Research, 34, 283-303.

Pereira, M. E. M., Marinotti, M., \& Luna, S. V. (2004). O compromisso do professor com a aprendizagem do aluno: contribuições da análise do comportamento. Em M. M. C. Hübner, Análise do comportamento para a educação: contribuições recentes. Santo André, SP: ESETec.

Ribeiro, M. L. (2010). A afetividade na relação educativa. Estudos de Psicologia, 27(3), 403-412.

Rodríguez, A., \& Hovde, K. (2002). The Challenge of School Autonomy: Supporting Principals Human Development. Department LCSHD Paper Series No. 77.

Sanzo, K. L., Sherman, W. H., \& Clayton, J. (2011). Leadership practices of successful middle school principals. Journal of Educational Administration, 49(1), 31-45.

Schmidt, M. J. (2010). Is there a place for emotions within leadership preparation programmes? Journal of Educational Administration, 48(5), 626-641. 
Sidman, M. (1999). Coerção e suas implicações (M. A. Andery \& T. M. Sério, Trad.). São Paulo: Editorial Psy II.

Skinner, B. F. (1998). Ciência e Comportamento Humano (10a ed.). São Paulo: Martins Fontes.

Smith, S. C., \& Pieli, P. K. (2006). School leadership: handbook for excellence in student learning (4a ed.). Califórnia: Thousand Oaks.

Somech, A. (2005). Directive Versus Participative Leadership: Two Complementary Approaches to Managing School Effectiveness. Educational Administration Quarterly, 41(5), 777-800.

Somech, A., \& Wenderow, M. (2006). The Impact of Participative and Directive Leadership on Teachers' Performance: The Intervening Effects of Job Structuring, Decision Domain, and Leader-Member Exchange. Educational Administration Quarterly, 42(5), 746-772.

Van Voorhis, F., \& Sheldon, S. (2004). Principals' roles in the development of US programs of school, family, and community partnerships. International Journal of Educational Research, 41, 55-70.
Wallace, J. (2010). Facing "reality": including the emotional in school leadership programmes. Journal of Educational Administration, 48(5), 595-610.

Weber, L. N. D. (2008). Interações entre família e desenvolvimento. Em L. N. D. Weber (Org.), Família e desenvolvimento: visões interdisciplinares. Curitiba: Ed. Juruá.

White, R., \& Lippitt, R. (1969). Comportamento do líder e reação dos membros em três "climas sociais". Em D. Cartwright, \& A. Zander, Dinâmica de Grupo: Pesquisa e Teoria (D. M. Leite \& M. L. M. Leite, Trad.). São Paulo: Ed. Herder. (Trabalho original publicado em 1967)

Yilmaz, E. (2010). The analysis of organizational creativity in schools regarding principals' ethical leadership characteristics. Procedia Social and Behavioral Sciences, 2, 3949-3953.

Zembat, R., Koçyigit, S., Tugluka, M. N., \& Dogan, H. (2010). The relationship between the effectiveness of preschools and leadership styles of school managers. Procedia Social and Behavioral Sciences, 2, 2269-2276.

Recebido em: 11/10/2011

Aprovado em: 19/01/2012

\section{Sobre as autoras}

Ana Priscila Batista (anapribatista@yahoo.com.br)

Departamento de Psicologia - UNICENTRO, Doutoranda do Programa de Pós-Graduação em Educação - UFPR, titulação atual: Mestre Endereço: Rua Imbituva, 430. Alto da Glória. Irati, PR. CEP: 84.500-000

Lidia Natalia Dobrianskyj Weber (lidiaw@uol.com.br)

Departamento de Psicologia - UFPR, Programa de Pós-Graduação em Educação - UFPR, titulação atual: Pós-Doutora.

Endereço: Praça Santos Andrade, 50/10. Universidade Federal do Paraná - UFPR, Departamento de Psicologia. Centro. Curitiba, PR. CEP: 80060-000

Trabalho realizado como parte da tese de doutorado da primeira autora e apresentado no X Congresso Nacional de Psicologia Escolar e Educacional, 2011. 